\title{
The Utilization and Costs of Grade D USPSTF Services in Medicare, 2007-2016
}

\author{
Carlos Irwin A. Oronce, MD, MPH ${ }^{1,2}$, A. Mark Fendrick, MD ${ }^{3}$, Joseph A. Ladapo, MD, PhD , \\ Catherine Sarkisian, MD, MSPH ${ }^{5,6}$, and John N. Mafi, MD, MPH, ${ }^{4,7}$
}

'VA Greater Los Angeles Healthcare System, Los Angeles, CA, USA; ${ }^{2}$ National Clinician Scholars Program, University of California Los Angeles (UCLA), Los Angeles, CA, USA; ${ }^{3}$ Department of Medicine, University of Michigan Medical School, Ann Arbor, MI, USA; ${ }^{4}$ Division of General Internal Medicine and Health Services Research, Department of Medicine, David Geffen School of Medicine at UCLA, Los Angeles, CA, USA; ${ }^{5}$ Division of Geriatrics, David Geffen School of Medicine at UCLA, Los Angeles, CA, USA; ${ }^{6}$ Geriatrics Research Education \& Clinical Center, VA Greater Los Angeles Healthcare System, Los Angeles, CA, USA; ${ }^{7}$ RAND Corporation, Santa Monica, CA, USA.

BACKGROUND: Low-value care, or patient care that offers no net benefit in specific clinical scenarios, is costly and often associated with patient harm. The US Preventive Services Task Force (USPSTF) Grade D recommendations represent one of the most scientifically sound and frequently delivered groups of low-value services, but a more contemporary measurement of the utilization and spending for Grade D services beyond the small number of previously studied measures is needed.

OBJECTIVE: To estimate utilization and costs of seven USPSTF Grade D services among US Medicare beneficiaries. DESIGN: We conducted a cross-sectional study of data from the National Ambulatory Medical Care Survey (NAMCS) from 2007 to 2016 to identify instances of Grade D services.

SETTING/PARTICIPANTS: NAMCS is a nationally representative survey of US ambulatory visits at non-federal and non-hospital-based offices that uses a multistage probability sampling design. We included all visits by Medicare enrollees, which included traditional fee-for-service, Medicare Advantage, supplemental coverage, and dual-eligible Medicare-Medicaid enrollees.

MAIN MEASURES: We measured annual utilization of seven Grade D services among adult Medicare patients, using inclusion and exclusion criteria from prior studies and the USPSTF recommendations. We calculated annual costs by multiplying annual utilization counts by mean per-unit costs of services using publicly available sources. KEY RESULTS: During the study period, we identified 95,121 unweighted Medicare patient visits, representing approximately 2.4 billion visits. Each year, these seven Grade D services were utilized 31.1 million times for Medicare beneficiaries and cost $\$ 477,891,886$. Three services-screening for asymptomatic bacteriuria, vitamin D supplements for fracture prevention, and colorectal cancer screening for adults over 85 years-comprised $\$ 322,382,772$, or two-thirds of the annual costs of the Grade D services measured in this study.

CONCLUSIONS: US Medicare beneficiaries frequently received a group of rigorously defined and costly low-value preventive services. Spending on low-value preventive care concentrated among a small subset of measures,

Received September 28, 2020

Accepted March 31, 2021

Published online April 14, 2021 representing important opportunities to safely lower US health care spending while improving the quality of care.

KEY WORDS: USPSTF; low-value care; Medicare; quality; value.

J Gen Intern Med 36(12):3711-8

DOI: $10.1007 / \mathrm{s} 11606-021-06784-8$

(c) Society of General Internal Medicine 2021

\section{INTRODUCTION}

Low-value care, or patient care that produces net harm or offers no net benefit in specific clinical scenarios, can lead to unnecessary spending and patient harm. ${ }^{1-7}$ An estimated $\$ 12.8$ to $\$ 26.5$ billion annually could be saved in the USA through interventions that reduce low-value services. ${ }^{8}$ A major challenge to reducing low-value care has been the identification of high-priority and evidence-based clinical targets. ${ }^{1}$ Given that prior studies often use loosely characterized definitions of low-value care, relying on the absence of evidence, frontline clinicians have challenged their clinical validity. ${ }^{9}$

The US Preventive Services Task Force (USPSTF) recommendations, on the other hand, are precisely defined and each grading accounts for the uncertainty and quality of evidence available. Because USPSTF preventive services impact millions of Americans, one potential group of services for intervention are those deemed Grade D, which the USPSTF actively discourages from providing (see Table 1 for grading definitions). ${ }^{11}$ The Grade D designation for a particular service requires sound evidence that the service either offers net harm or offers no net benefit to asymptomatic patients. Grade D services, therefore, are among the most rigorously developed lists of low-value services to target for reduction. Data describing the utilization or costs of Grade D services within Medicare are lacking. While studies have examined low-value care in Medicare, these studies used data as recent as 2011 or focused on one to three services. ${ }^{4,5} 7$ As interest grows among policymakers to deter the use of low-value care, a more recent and broader understanding of the extent of Grade D services is needed. 
Table 1 Definitions of the USPSTF Grading System ${ }^{10}$

\begin{tabular}{lll}
\hline \hline Grade & Definition & Recommendation \\
\hline A & $\begin{array}{l}\text { The USPSTF recommends } \\
\text { the service. There is high } \\
\text { certainty that the net } \\
\text { benefit is substantial. }\end{array}$ & Offer or provide this service. \\
Bhe USPSTF recommends & Offer or provide this service. \\
the service. There is high & \\
certainty that the net & \\
benefit is moderate or there & \\
is moderate certainty that & \\
the net benefit is moderate & \\
to substantial. & \\
The USPSTF recommends & Offer or provide this service \\
selectively offering or \\
providing this service to \\
individual patients based \\
on professional judgment \\
and patient preferences. \\
$\begin{array}{l}\text { There is at least moderate } \\
\text { certainty that the net } \\
\text { benefit is small. }\end{array}$
\end{tabular}

Hence, the objective of this study was to quantify the utilization and costs of selected Grade D services among Medicare beneficiaries. We used a nationally representative survey of outpatient visits across a 10-year period and constructed measures of Grade D services using existing literature and the USPSTF recommendations.

\section{STUDY DATA AND METHODS Data Source and Collection}

We used data from 2007 to 2016 from the National Ambulatory Medical Care Survey (NAMCS), a nationally representative survey of ambulatory visits to non-federal office-based practices in the USA. The National Center for Health Statistics (NCHS) administers NAMCS annually and employs a multistage probability design to sample visits to office-based clinicians. Physician offices and representatives of the US Census Bureau abstract data from the medical record with a standardized survey instrument. Information collected includes reasons for visit (chief complaint and two secondary complaints), diagnosis codes (International Classification of Diseases, Ninth and Tenth Editions), demographic information, expected payers, selected laboratory tests, imaging, and medications (both prescription and over-the-counter medications) either ordered or continued at the visit. Indicators for selected chronic diseases are included in addition to diagnosis codes. The NCHS calculates survey weights for visits based on the inverse probability of selection at each sampling stage in order to derive national estimates. Annual response rates during the study period ranged from 46 to $64 \%$.

Eligible visits included beneficiaries aged 18 years and older in which Medicare was listed as a payer (including feefor-service Medicare, Medicare Advantage, those with supplemental Medicare plans, and dual-eligible Medicare-Medicaid beneficiaries). NAMCS has been frequently utilized as a nationally representative data source for studying low-value care. $^{12-16}$

\section{Main Outcome Measures}

We selected seven USPSTF Grade D services that could be feasibly identified in NAMCS. While we examined all Grade D services at the time of the analysis $(n=20)$, we excluded measures that could not be replicated with the available diagnosis codes, reason for visit codes (corresponding to chief complaints and other secondary symptoms), and indicators for certain services (such as colonoscopy or sigmoidoscopy) $(n=13)$. Additionally, some services were coded too infrequently in the data to be deemed reliable, such as carotid ultrasonography for carotid artery stenosis screening $(n=4)$. The seven services that could be reliably measured were as follows: (1) asymptomatic bacteriuria screening in nonpregnant adults, (2) cardiovascular disease screening in low-risk adults with either rest or stress electrocardiography, (3) cervical cancer screening in women over 65 years old with Papanicolaou or HPV testing, (4) colorectal cancer screening in adults over 85 years old with either colonoscopy or sigmoidoscopy, (5) COPD screening in asymptomatic adults with peak flow or spirometry, (6) prostate cancer screening with prostate-specific antigen testing in men 75 years old and older, and (7) vitamin D supplementation for fracture prevention among postmenopausal women.

In calculating a specific measure, NAMCS data were pooled across years that the indicator variable for a test or service was available and a USPSTF recommendation existed. We used 2007 through 2016 for the cervical cancer screening and cardiovascular disease screening measures as indicators for these services were available. In the case of colorectal cancer screening, a variable for colonoscopy and/or sigmoidoscopy was available from 2009 to 2016 . We supplemented this definition by including ICD-9 and ICD-10 codes used during screening encounters. For consistency, we conservatively used the prostate cancer screening recommendation from 2008 as there have been two changes since then (with a Grade D recommendation for screening at any age in 2012 and later to 70 years and older in 2018). Because the USPSTF issued the recommendation in the second half of 2008, we used 2009 to 2016 years for this measure. For the 
asymptomatic bacteriuria measure, we used 2009 to 2016 data as these were years where the urinalysis or urine culture indicators were available. For COPD screening, we used 2012 to 2016 because 2012 was the first year the spirometry indicator was available in the data. Finally, 2013 to 2016 data were used for the vitamin D supplementation measure because 2013 was the first year the USPSTF issued a recommendation against its use for osteoporosis prevention among postmenopausal women. All measures were studied only when a Grade $\mathrm{D}$ recommendation was active.

To account for the clinical nuance required to identify these services, we excluded visits with competing diagnoses or other clinical information. For the asymptomatic bacteriuria screening measure, we excluded encounters that reported symptoms localizing to the urinary tract. These included reason for visit codes or ICD-9 or ICD-10 diagnosis codes corresponding to hematuria, nocturia, painful urination, and burning. We further excluded patients who were pregnant using the NAMCS indicator for pregnancy status along with ICD-9 or ICD-10 codes for pregnancy or prenatal care. To construct the population eligible for cardiovascular screening, we excluded encounters with diagnostic codes corresponding to any cardiovascular condition, such as dyslipidemia, hypertension, coronary artery disease, and ischemic stroke. We also excluded visits with reason for visit or diagnostic codes denoting clinical features prompting a diagnostic work up, such as syncope, palpitations, edema, murmurs, or history of diabetes. Among those eligible for the COPD screening measure, we excluded those with respiratory symptoms, such as cough or wheezing, and those with a history of any pulmonary disorder, including asthma, obstructive lung disease, and interstitial lung disease. For the vitamin D supplementation measure, we excluded patients with a diagnosis of osteoporosis, vitamin D deficiency, or conditions associated with increased risk for malabsorption such as inflammatory bowel disease, celiac disease, or post-bariatric surgery.

Because the USPSTF recommendations apply to averagerisk patients, we further excluded patients at high risk for cancer under the cancer screening measures. For cervical cancer screening, we excluded encounters among women with a history of abnormal Papanicolaou tests, positive HPV tests, cervical dysplasia, any gynecological malignancy or carcinoma in situ, and human immunodeficiency virus, or presenting with alarm symptoms such as vaginal bleeding. For the colorectal cancer screening measure, we excluded visits where a colonoscopy or sigmoidoscopy would be recommended for diagnostic purposes, such as gastrointestinal bleeding or a diagnosis of iron deficiency anemia. We further excluded individuals that were not at average risk for colon cancer, including patients with any inflammatory bowel disease diagnosis, a personal or family history of colonic polyps, Lynch syndrome, and familial adenomatous polyposis. Similarly, we excluded patients from the prostate cancer screening measure if they had a personal or family history of prostate cancer. To minimize misclassification of an appropriately ordered service as low value, we maximized the number of exclusions to construct the most conservative measures possible. The complete list of exclusion criteria and associated codes is included in the appendix.

To calculate annual expenditures, we multiplied the weighted number of visits in which a service was ordered by the perunit Medicare price for that individual service. We searched for the best publicly available sources for Medicare prices in February 2020, which included publication dates ranging from 2015 to 2020 (see appendix for the list of price sources). When ranges were available, we used the lower bound to derive more conservative estimates. These encompass the average national price paid to physicians and do not specifically reflect out-ofpocket spending.

\section{Statistical Analysis}

We report age, gender, race/ethnicity, and payer information by receipt of any Grade D service. We collapsed race/ethnicity into mutually exclusive categories of non-Hispanic white, non-Hispanic black, Hispanic/Latino, and other. Visits where Medicare and private insurance were listed as payers were categorized as Medicare plus supplemental private insurance and visits with Medicare and Medicaid listed were categorized as dual-eligible. We report annualized weighted counts of utilization for each measure and their $95 \%$ confidence intervals, using standard methods to account for weighting and the complex survey design. In accordance with NCHS requirements, we only calculated utilization if the unweighted number of sampled visits for a service was 30 or higher and with a relative standard error of 0.30 or less. ${ }^{17,18}$ We performed all analyses using SAS (version 9.4) and the UCLA IRB deemed this study exempt from human subjects research.

\section{STUDY RESULTS}

From 2007 to 2016, we identified 95,121 unweighted Medicare patient visits within NAMCS, representing approximately 2.4 billion visits. The average age was 72.2 years and $57.4 \%$ of patients were female. Table 2 illustrates the characteristics of patients seen at visits based on whether a Grade D service was utilized. Across visits where Grade D services were used, approximately $8.5 \%$ of patients were non-Hispanic black and $10.6 \%$ were Hispanic, compared to $8.9 \%$ non-Hispanic black and $8.2 \%$ Hispanic among visits where no Grade D service was used. With respect to payer, patients with Medicare-only coverage (which include both traditional fee-for-service and Medicare Advantage enrollees) comprised a slightly higher proportion of Grade D visits at $56.4 \%$ versus $54.8 \%$ among visits without a Grade D service utilized.

The utilization of the selected Grade D services exceeded 30 million episodes annually, averaging approximately 13 services per 100 Medicare ambulatory visits. Table 3 shows the count for each Grade D service. The annual count ranged from 137,441 (95\% CI: 62,736-212,147) for colon cancer 
Table 2 Weighted Characteristics of Medicare Beneficiaries at Visits, 2007-2016

\begin{tabular}{|c|c|c|}
\hline Characteristics & $\begin{array}{l}\text { Receiving Grade D } \\
\text { preventive service }^{\text {a }} \\
(n=6888)^{\mathbf{b}}\end{array}$ & $\begin{array}{l}\text { Not receiving Grade } \\
\text { D preventive service } \\
(n=\mathbf{8 8 , 2 3 3})^{\mathbf{b}}\end{array}$ \\
\hline Weighted visits (\%) & $188,567,988(7.9)$ & $2,203,570,920(92.1)$ \\
\hline Age (years, mean) & 73.0 & 72.2 \\
\hline Female sex $(\%)$ & 62.6 & 56.9 \\
\hline \multicolumn{3}{|l|}{ Race/ethnicity (\%) } \\
\hline $\begin{array}{l}\text { Non-Hispanic } \\
\text { white }\end{array}$ & 77.8 & 78.8 \\
\hline $\begin{array}{l}\text { Non-Hispanic Af- } \\
\text { rican American }\end{array}$ & 8.5 & 8.9 \\
\hline Hispanic & 10.6 & 8.2 \\
\hline Other & 3.1 & 4.1 \\
\hline \multicolumn{3}{|l|}{ Payer type $(\%)$} \\
\hline Medicare-only & 56.4 & 54.8 \\
\hline $\begin{array}{l}\text { Medicare + } \\
\text { supplemental } \\
\text { private }\end{array}$ & 37.4 & 37.8 \\
\hline Dual-eligible & 6.2 & 7.4 \\
\hline
\end{tabular}

${ }^{a}$ Visits are counted as receiving Grade D preventive services if they received any of the selected seven services during the study period. If multiple Grade D services were ordered at a single encounter, then the visit was counted once

${ }^{b}$ Unweighted sample size

screening in adults 85 years and older to $14,144,166$ (95\% CI: $12,711,424-15,576,907)$ for asymptomatic bacteriuria screening. The top two Grade D services, asymptomatic bacteriuria screening and vitamin D supplementation for fraction prevention among postmenopausal women, were used in high volume, comprising $83.9 \%$ of the annual count for the seven Grade D services.

The total annual costs of these Grade D services averaged \$477.9 million (95\% CI: \$377.2 million-\$578.6 million, see Table 3). Across all Medicare visits in which these services were utilized, they contributed an additional \$25 per visit on average. Some services comprised a disproportionate share of costs relative to their volume. For example, colon cancer screening comprised $0.4 \%$ of the annual count of these Grade D services, but $14.5 \%$ of the costs. The three services that contributed the most to annual costs included (1) screening for asymptomatic bacteriuria, (2) vitamin D supplements for fracture prevention, and (3) colorectal cancer screening among adults $>85$ years, which comprised $67.5 \%$ of spending and $84.4 \%$ of the utilization for these services (Table 3 ).

\section{DISCUSSION}

In this nationally representative analysis of outpatient visits made by Medicare beneficiaries over a 10 -year period, a group of seven rigorously defined low-value preventive services were utilized over 30 million times each year, totaling over $\$ 477$ million in estimated annual health care spending. We found that the two Grade D services that were highest in volume were also the two services that contributed most to total annual spending for the seven Grade D services. Additionally, we found that colon cancer screening for those over 85 years was used the least but ranked among the top three most costly services. While much attention to low-value care in Medicare has previously focused on a large number of measures that included a few Grade D recommendations, our study identified additional measures that comprise a relatively large proportion of spending, which reflect important targeted opportunities to safely reduce spending while improving the quality of care.

Our findings differ slightly compared to prior work that examined low-value preventive services in Medicare. For example, Grade D prostate cancer screening was ordered during approximately $1,786,701$ visits in this study, which is higher than a previous estimate of about 762,000 instances in $2009{ }^{4}$ In studies that examined screening from 2013 to 2016, estimates ranged between 9.8 and $18.6 \%$ of eligible men. ${ }^{19,20}$ While these proportions of Grade D prostate cancer screening are higher than the $4.2 \%$ of eligible visits in our study, it is important to note that our units of analysis were visits among Medicare beneficiaries seeking care rather than all Medicare beneficiaries. Therefore, the differences in screening may be due to differences in levels of analysis (visit-level versus patient-level) and the number of years used to derive estimates. With regards to Grade D colon cancer screening, our estimate of 137,441 instances is lower than the prior estimate of over 244,000; however, our specification more conservatively excluded additional clinical conditions. ${ }^{4}$ Given the limitations of claims data in capturing symptoms, data derived from medical records, such as NAMCS, offer greater detail and the ability to examine symptoms in developing exclusions. ${ }^{21-29}$ The potentially enhanced specificity of our findings is a particular strength as we sought to avoid misclassifying encounters as low value given the potential clinical and policy implications of how low-value care is defined.

While the costs of services examined here is considerable, the full extent of utilization and costs of low-value preventive services is likely larger. Not all USPSTF Grade D services were included in this analysis, and these findings are limited to the direct costs of each service, not including those associated with subsequent harms and other unnecessary downstream testing and/or referrals. For instance, approximately $0.5 \%$ of patients undergoing prostate cancer screening experience complications of incontinence or impotence from prostate surgery each year according to a USPSTF systematic review. ${ }^{11}$ Extrapolated to our findings, these low-value prostate cancer screening tests would have caused an estimated 89,335 additional older Americans to develop incontinence or impotence during the study period. Even when no immediate complications result, unexpected findings from low-value screening often trigger further unnecessary tests in "cascades of care," adding to costs and potential harms. ${ }^{30}$

Our findings also clarify and highlight an under-recognized source of low-value care for which strong evidence of no benefit exists. The USPSTF Grade D definitions of lowvalue care cite evidence of absence of benefit, which is more robust than looser definitions simply citing an absence of 


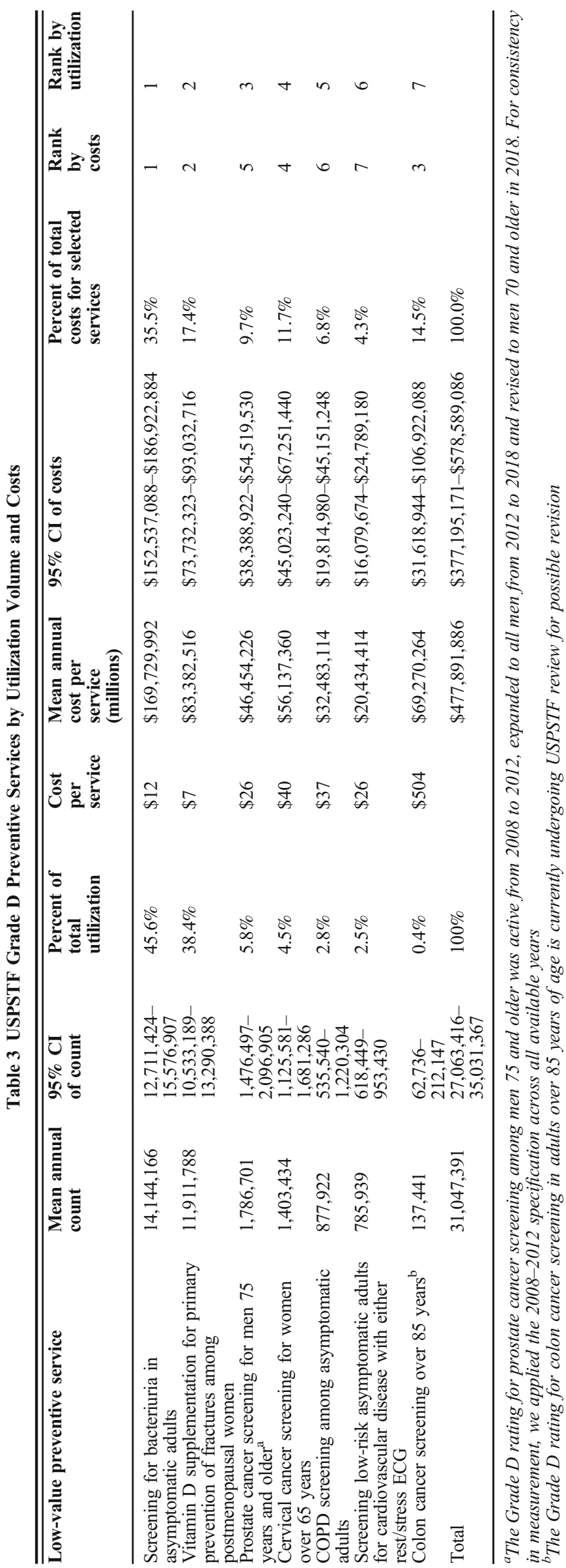


evidence. ${ }^{31}$ Lists of low-value services in general are subject to criticism given the infrequency of some of the services listed, the unclear potential impact for improving quality, and the weak evidence in developing some of them. ${ }^{1,9}$ These lists are often methodologically closer to Grade I services where evidence is uncertain or evidence to identify benefit or harm is lacking. While an important nuance, many would consider Grade I low-value care under broader and potentially less widely accepted definitions. Moreover, the USPSTF does not consider the cost of services in making its determinations, focusing solely on clinical benefits versus harms. ${ }^{11}$ Hence, efforts to reduce Grade D services can also avoid ethically complex debates about rationing and cost-effectiveness.

Second, as policymakers consider options to improve value for Medicare beneficiaries, reducing Grade D services can be incorporated into payment reform. Canada has set an important precedent by successfully eliminating payment for population-based vitamin D laboratory screening, leading to marked reductions in low-value vitamin D testing. ${ }^{32}$ In the USA, the Affordable Care Act grants CMS authority to decline payment for Grade D services; however, CMS has not yet exercised this provision. ${ }^{33} \mathrm{CMS}$ could implement such a policy through a randomized pilot demonstration to reduce potentially harmful asymptomatic bacteriuria screening, with careful attention to stakeholder engagement, valid measurement, and unintended consequences (e.g., upcoding, financial toxicity to patients, or widening inequities in evidence-based care). ${ }^{2,34,35}$ Implementation would likely rely on administrative data using ICD-10 diagnosis codes, which have demonstrated reasonably strong sensitivity and specificity for lowvalue care measures when compared with manual chart review by professional coders. ${ }^{36}$

If such a pilot program is proven safe and effective, rolling it out nationally has the potential to simultaneously protect older Americans from harm and produce cost-savings, which can be directly tied to further cost-sharing reductions for evidencebased, high-value care (e.g., eliminating cost-sharing for lifesaving blood pressure medications ${ }^{37}$ ). Tying the reduction of low-value care directly to the lowering of financial barriers to high-value care serves as a compelling ethical justification for maximizing clinical benefits for patients, while preserving financial sustainability for the Medicare program.

Finally, the COVID-19 pandemic has introduced additional constraints on Medicare spending. Many vulnerable Medicare beneficiaries face potentially catastrophic expenses during the current crisis and reducing low-value care is an important step to prevent exacerbating the impact of financial toxicity. ${ }^{38}$ The continued ordering of these low-value services despite a Grade $D$ recommendation, however, underscores the challenge of deimplementation in the post-pandemic period. Low-value care remains an intractable problem for a wide array of reasons, including clinician factors (e.g., lawsuit fears, time pressure, uncertainty), patient factors (assumptions that more care equals better care), and health system factors (institutional culture, fee-for-service payments). ${ }^{5,14,39-50}$ As the RAND
Health Insurance Experiment demonstrated, the difficulty of reducing low-value care while avoiding an undesirable simultaneous reduction in high-value care poses a major challenge. ${ }^{51,52}$ This is why rigorously defined measures of lowvalue care such as Grade D services can help refine currently blunt policy tools, such as cost-sharing, that undesirably lower both high and low-value care simultaneously.

Ultimately, while there remains an evidence gap in understanding the effectiveness of most interventions, a 2017 systematic review of interventions to reduce low-value care found that multipronged interventions are more effective than single interventions. ${ }^{53}$ Strategies that combine novel payment reforms, such as those described above or accountable care organizations, with supply-side interventions, including physician education, engagement, and seamless alerts embedded in the electronic health record, might be the most effective approach in reducing exposure to the harms of low-value care for Medicare beneficiaries. ${ }^{2,50,54-56}$ Reducing expenditures on low-value services provides a rare cost-neutral opportunity to redesign Medicare policies aimed to increase the use of high-value services.

\section{Limitations}

There are several limitations to note. First, our method of estimating Medicare spending on Grade D services may be less precise compared to claims data which capture reimbursement of services rendered. However, using claims to estimate the utilization of Grade D services may potentially misclassify many services, as such data lack key clinical information that informs whether or not a service is indicated. ${ }^{21-23}$ For example, use of claims data alone had $56 \%$ sensitivity for identifying UTIs compared to a combination of claims and clinical information. ${ }^{29}$ In contrast, data for symptoms are considered more accurate in medical records than administrative claims data. Additionally, previous assessments found that NAMCS displays reasonably strong validity with respect to diagnoses and procedures. ${ }^{25,26}$

Second, NAMCS may underestimate national utilization rates by not capturing non visit-based orders and overestimate utilization by measuring some services that were ordered, but not necessarily rendered and reimbursed. Additionally, because the NAMCS encounter form does not distinguish between over-the-counter and prescription medications, some of the vitamin D medications may be over-the-counter. Nevertheless, patient-driven over-the-counter medications reflect a common and under-recognized source of low-value care (e.g., NSAIDs for patients with heart disease) and physicians can still discourage use of these medications during ambulatory visits. Third, while the survey accounts for non-response bias, NAMCS response rates have declined over time. We followed the NCHS recommendations for statistical analysis and strengthened our sample by pooling several years of data for each measure. Fourth, NAMCS only reflects office-based ambulatory care (approximately $90 \%$ of U.S. ambulatory care) 
and does not include hospital-based ambulatory care (approximately $10 \%$ of U.S. ambulatory care). ${ }^{14,}{ }^{25}$ Finally, patients are not tracked longitudinally in NAMCS. This may lead to overestimation of Grade D cervical cancer screening since the measure does not apply to women with inadequate screening in the decade prior to age 65 , a group we could not identify and exclude.

\section{CONCLUSION}

Medicare beneficiaries frequently received several rigorously defined low-value preventive services, costing over $\$ 477$ million in estimated US health care spending each year. The negative clinical impact and total costs of these low-value services are likely larger as these findings capture neither all D-rated services nor the cascade of downstream health care utilization after their use. Reducing the use of Grade D services represents an opportunity to improve patient-centered outcomes while safely reducing US health care spending.

Supplementary Information The online version contains supplementary material available at https://doi.org/10.1007/s11606-02106784-8.

Acknowledgements: The authors would like to thank John Hanaway of Milliman for his help in gathering per-unit prices from publicly available sources, Rong Guo for analytical support, and Sara Delgado for her help in manuscript preparation and administrative support.

Corresponding Author: John N. Mafi, MD, MPH; Division of General Internal Medicine and Health Services Research, Department of Medicine, David Geffen School of Medicine at UCLA, Los Angeles, CA, USA (e-mail: jmafi@mednet.ucla.edu).

Funding Carlos Irwin A. Oronce, $M D, M P H$, is supported by the Veterans Affairs (VA) Office of Academic Affiliations through the VA/ National Clinician Scholars Program.

Joseph A. Ladapo is supported by the National Institute on Drug Abuse (R01 DA045688), the National Heart, Lung, and Blood Institute (UO1 HL142104), and the National Institute on Minority Health and Health Disparities (RO1 MDO11544).

Catherine Sarkisian, MD, MSHS, is supported by a National Institute on Aging of the National Institutes of Health Midcareer Award in Patient-Oriented Research (1K24AG047899), the UCLA Resource Center for Minority Aging Research/Center for Health Improvement of Minority Elders (RCMAR/CHIME, P30-AG021684), and the NIH/ National Center for Advancing Translational Science (NCATS) UCLA CTSI (UL1TROO1881). Support for this paper has also been provided to the UCLA Value-Based Care Research Consortium (VBCRC) from the UCLA Vatche \& Tamar Manoukian Division of Digestive Diseases. John N. Mafi, MD, MPH, is supported by the UCLA Clinical and Translational Science Institute (CTSI) KL2 Award KL2TROO1882 (PI: Mitchell Wong), NIA K76 Beeson Emerging Leaders career development award 1K76AG064392-01A1 (PI: John Mafi), NIA RO1 R01AG070017-01 Award (PI: John Mafi), Arnold Ventures, and the National Institutes on Aging R01AG059815-01 (PI: Catherine Sarkisian).

\section{Declarations:}

Conflict of Interest: A. Mark Fendrick, MD is a codeveloper of the Milliman MedInsight Health Waste Calculator and receives royalties from its sale. He has been a consultant for AbbVie, Amgen, Centivo, Community Oncology Association, Covered California, EmblemHealth,
Exact Sciences, Freedman Health, GRAIL, Harvard University, Health \& Wellness Innovations, Health at Scale Technologies, MedZed, Penguin Pay, Risalto, Sempre Health, the State of Minnesota, US Department of Defense, Virginia Center for Health Innovation, Wellth, and Zansors; and has received research support from the Agency for Healthcare Research and Quality, Boehringer-Ingelheim, Gary and Mary West Health Policy Center, Arnold Ventures, National Pharmaceutical Council, Patient-Centered Outcomes Research Institute, Pharmaceutical Research and Manufacturers of America, the Robert Wood Johnson Foundation, the State of Michigan, and the Centers for Medicare and Medicaid Services.

Disclaimer: The contents do not represent the views of the US Department of Veterans Affairs or the United States Government.

\section{REFERENCES}

1. Kerr EA, Kullgren JT, Saini SD. Choosing Wisely: How To Fulfill The Promise In The Next 5 Years. Health affairs (Project Hope). 2017;36(11):2012-2018.

2. Mafi JN, Parchman M. Low-value care: an intractable global problem with no quick fix. BMJ Qual Saf. 2018;27(5):333-336.

3. Mafi JN, Russell K, Bortz BA, Dachary M, Hazel WA, Fendrick AM. Low-Cost, High-Volume Health Services Contribute The Most To Unnecessary Health Spending. Health Affairs. 2017;36(10):1701-1704.

4. Schwartz AL, Landon BE, Elshaug AG, Chernew ME, McWilliams JM. Measuring Low-Value Care in Medicare. JAMA internal medicine. 2014;174(7):1067-1076.

5. Colla CH, Morden NE, Sequist TD, Schpero WL, Rosenthal MB. Choosing Wisely: Prevalence and Correlates of Low-Value Health Care Services in the United States. J Gen Intern Med. 2015;30(2):221-228.

6. Rosenberg A, Agiro A, Gottlieb M, et al. Early Trends Among Seven Recommendations From the Choosing Wisely Campaign. JAMA internal medicine. 2015;175(12):1913-1920.

7. Mafi JN, Reid RO, Baseman LH, et al. Trends in Low-Value Health Service Use and Spending in the US Medicare Fee-for-Service Program, 2014-2018. JAMA Network Open. 2021;4(2):e2037328-e2037328.

8. Shrank WH, Rogstad TL, Parekh N. Waste in the US Health Care System: Estimated Costs and Potential for Savings. JAMA. 2019;322(15):1501-1509.

9. Garner S, Docherty M, Somner J, et al. Reducing ineffective practice: challenges in identifying low-value health care using Cochrane systematic reviews. Journal of health services research \& policy. 2013;18(1):612.

10. United States Preventive Services Task Force. Grade Definitions. 2012; https://www.uspreventiveservicestaskforce.org/uspstf/grade-definitions. Accessed May 3, 2020.

11. United States Preventive Services Task Force. Recommendations for Primary Care Practice. 2020; https://www.uspreventiveservicestaskforce.org/Page/ Name/recommendations. Accessed May 3, 2020.

12. Mafi JN, McCarthy EP, Davis RB, Landon BE. Worsening trends in the management and treatment of back pain. JAMA internal medicine. 2013;173(17):1573-1581.

13. Ladapo JA, Blecker S, Douglas PS. Physician decision making and trends in the use of cardiac stress testing in the United States: an analysis of repeated cross-sectional data. Ann Intern Med. 2014;161(7):482-490.

14. Mafi JN, Wee CC, Davis RB, Landon BE. Association of Primary Care Practice Location and Ownership With the Provision of Low-Value Care in the United States. JAMA internal medicine. 2017;177(6):838-845.

15. Barnett ML, Linder JA, Clark CR, Sommers BD. Low-Value Medical Services in the Safety-Net Population. JAMA internal medicine. 2017;177(6):829-837.

16. Oronce CIA, Fortuna RJ. Differences in Rates of High-Value and LowValue Care Between Community Health Centers and Private Practices. J Gen Intern Med. 2019.

17. National Center for Health Statistics. Using ultimate cluster models with NAMCS and NHAMCS public use files. 2004; https://www.cdc.gov/ nchs/data/ahcd/ultimatecluster.pdf. Accessed May 3, 2020.

18. National Center for Health Statistics. Ambulatory Health Care Data Datasets and Documentation. https://www.cdc.gov/nchs/ahcd/ datasets_documentation_related.htm. Accessed May 3, 2020. 
19. Magnani CJ, Li K, Seto T, et al. PSA Testing Use and Prostate Cancer Diagnostic Stage After the 2012 U.S. Preventive Services Task Force Guideline Changes. Journal of the National Comprehensive Cancer Network : JNCCN. 2019;17(7):795-803.

20. Bynum J, Passow H, Carmichael D, Skinner J. Exnovation of Low Value Care: A Decade of Prostate-Specific Antigen Screening Practices. Journal of the American Geriatrics Society. 2019;67(1):29-36.

21. Heintzman J, Bailey SR, Hoopes MJ, et al. Agreement of Medicaid claims and electronic health records for assessing preventive care quality among adults. Journal of the American Medical Informatics Association : JAMIA. 2014;21(4):720-724.

22. Devoe JE, Gold R, McIntire P, Puro J, Chauvie S, Gallia CA. Electronic health records vs Medicaid claims: completeness of diabetes preventive care data in community health centers. Annals of family medicine. 2011;9(4):351-358.

23. MacLean CH, Louie R, Shekelle PG, et al. Comparison of administrative data and medical records to measure the quality of medical care provided to vulnerable older patients. Med Care. 2006;44(2):141-148.

24. Psaty BM, Delaney JA, Arnold AM, et al. Study of Cardiovascular Health Outcomes in the Era of Claims Data: The Cardiovascular Health Study. Circulation. 2016;133(2):156-164.

25. Asao K, McEwen LN, Lee JM, Herman WH. Ascertainment of outpatient visits by patients with diabetes: The National Ambulatory Medical Care Survey (NAMCS) and the National Hospital Ambulatory Medical Care Survey (NHAMCS). J Diabetes Complications. 2015;29(5):650-658.

26. Gilchrist VJ, Stange KC, Flocke SA, McCord G, Bourguet CC. A comparison of the National Ambulatory Medical Care Survey (NAMCS) measurement approach with direct observation of outpatient visits. Med Care. 2004;42(3):276-280.

27. Administration USFD. Frameowrk for FDA's Real-World Evidence Program. 2018.

28. Kim DH, Lee J, Kim CA, et al. Evaluation of algorithms to identify delirium in administrative claims and drug utilization database. Pharmacoepidemiology and drug safety. 2017;26(8):945-953.

29. Landers T, Apte M, Hyman S, Furuya Y, Glied S, Larson E. A comparison of methods to detect urinary tract infections using electronic data. Joint Commission journal on quality and patient safety. 2010;36(9):411-417.

30. Ganguli I, Lupo C, Mainor AJ, et al. Prevalence and Cost of Care Cascades After Low-Value Preoperative Electrocardiogram for Cataract Surgery in Fee-for-Service Medicare Beneficiaries. JAMA internal medicine. 2019.

31. Verkerk EW, Tanke MAC, Kool RB, van Dulmen SA, Westert GP. Limit, lean or listen? A typology of low-value care that gives direction in deimplementation. International journal for quality in health care : journal of the International Society for Quality in Health Care. 2018;30(9):736739

32. Henderson J, Bouck Z, Holleman R, et al. Comparison of Payment Changes and Choosing Wisely Recommendations for Use of Low-Value Laboratory Tests in the United States and Canada. JAMA internal medicine. 2020

33. Buxbaum JD, Fendrick AM, Mafi JN. Tackling Low-Value Care: A New "Top Five" for Purchaser Action. Health Affairs Blog. DOI: https://doi. org/10.1377/hblog20171117.664355. 2017

34. Taleb NN. Antifragile: Things That Gain from Disorder (Incerto). Random House Trade Paperbacks; Reprint edition (January 28, 2014).

35. Sivashanker K, Gandhi TK. Advancing Safety and Equity Together. N Engl J Med. 2020;382(4):301-303.

36. Angiolillo J, Rosenbloom ST, McPheeters M, Seibert Tregoning G, Rothman RL, Walsh CG. Maintaining automated measurement of Choosing Wisely adherence across the ICD 9 to 10 transition. J Biomed Inform. 2019;93:103142.

37. Chandra A, Flack E, Obermeyer Z. The Health Costs of Cost-Sharing. NBER Working Paper. 2021(w28439).
38. Freed M, Cubanski J, Neuman T. Medicare Beneficiaries Without Supplemental Coverage Are at Risk for Out-of-Pocket Costs Relating to COVID-19 Treatment. 2020; https://www.kff.org/coronavirus-policywatch/medicare-beneficiaries-without-supplemental-coverage-are-atrisk-for-out-of-pocket-costs-relating-to-covid-19-treatment/. Accessed May 10, 2020.

39. Chen C, Petterson S, Phillips R, Bazemore A, Mullan F. Spending patterns in region of residency training and subsequent expenditures for care provided by practicing physicians for Medicare beneficiaries. Jama. 2014;312(22):2385-2393.

40. Morgan DJ, Leppin AL, Smith CD, Korenstein D. A Practical Framework for Understanding and Reducing Medical Overuse: Conceptualizing Overuse Through the Patient-Clinician Interaction. J Hosp Med. 2017; 12(5):346-351.

41. Morgan DJ, Dhruva SS, Wright SM, Korenstein D. 2016 Update on Medical Overuse: A Systematic Review. JAMA Intern Med. 2016;176(11): 1687-1692.

42. Smith CD, Korenstein D. Harnessing the Power of Peer Pressure to Reduce Health Care Waste and Improve Clinical Outcomes. Mayo Clin Proc. 2015;90(3):311-312.

43. Korenstein D, Falk R, Howell EA, Bishop T, Keyhani S. Overuse of health care services in the United States: an understudied problem. Arch Intern Med. 2012;172(2):171-178.

44. Colla CH, Mainor AJ, Hargreaves C, Sequist T, Morden N. Interventions Aimed at Reducing Use of Low-Value Health Services: A Systematic Review. Med Care Res Rev. 2016.

45. Jena AB, Schoemaker L, Bhattacharya J, Seabury SA. Physician spending and subsequent risk of malpractice claims: observational study. BMJ. 2015;351:h5516.

46. Gidengil CA, Mehrotra A, Beach S, Setodji C, Hunter G, Linder JA. What Drives Variation in Antibiotic Prescribing for Acute Respiratory Infections? J Gen Intern Med. 2016.

47. Allison JJ, Kiefe CI, Cook EF, Gerrity MS, Orav EJ, Centor R. The association of physician attitudes about uncertainty and risk taking with resource use in a Medicare HMO. Med Decis Making. 1998;18(3):320329.

48. Shah BR, Cowper PA, Brien SM, et al. Association between physician billing and cardiac stress testing patterns following coronary revascularization. Jama. 2011;306(18): 1993-2000.

49. Norton WE, Chambers DA. Unpacking the complexities of deimplementing inappropriate health interventions. Implementation science : IS. 2020;15(1):2.

50. Colla CH. Swimming against the current-what might work to reduce lowvalue care? N Engl J Med. 2014;371(14):1280-1283.

51. Newhouse JP, Manning WG, Morris CN, et al. Some interim results from a controlled trial of cost sharing in health insurance. N Engl J Med. 1981;305(25):1501-1507.

52. Brook RH, Ware J, John E, Rogers WH, et al. Does Free Care Improve Adults' Health? N Engl J Med. 1983;309(23):1426-1434.

53. Colla CH, Mainor AJ, Hargreaves C, Sequist T, Morden N. Interventions Aimed at Reducing Use of Low-Value Health Services: A Systematic Review. Med Care Res Rev. 2017;74(5):507-550.

54. Kim DD, Ollendorf DA, Neumann PJ, Fendrick AM. Crisis into opportunity: can COVID-19 help set a path to improved health care efficiency? The American journal of managed care. 2020;26(9):369-370.

55. Meeker D, Knight TK, Friedberg $\mathbf{M W}$, et al. Nudging guidelineconcordant antibiotic prescribing: a randomized clinical trial. JAMA internal medicine. 2014;174(3):425-431.

56. Schwartz AL, Chernew ME, Landon BE, McWilliams JM. Changes in Low-Value Services in Year 1 of the Medicare Pioneer Accountable Care Organization Program. JAMA internal medicine. 2015;175(11):18151825.

Publisher's Note: Springer Nature remains neutral with regard to jurisdictional claims in published maps and institutional affiliations. 